\title{
Insurance Discrimination on the Basis of Health Status: An Overview of Discrimination Practices, Federal Law and Federal Reform Options
}

Sara Rosenbaum

George Washington University, sarar@gwu.edu

This paper can be downloaded free of charge from:

http://scholarship.law.georgetown.edu/ois_papers/24 


\section{Legal Solutions in Health Reform}

Insurance Discrimination

on the Basis of Health

Status: An Overview of

Discrimination Practices,

Federal Law, and Federal

Reform Options

Sara Rosenbaum, JD 


\section{O’Neill Institute}

for National and Global Health Law

\section{THE LINDA D. AND TIMOTHY J. O’NEILL INSTITUTE FOR NATIONAL AND GLOBAL HEALTH LAW}

AT

GEORGETOWN LAW

The O'Neill Institute for National and Global Health Law at Georgetown University is the premier center for health law, scholarship and policy. Housed at Georgetown University Law Center, in the heart of the nation's capital, the Institute has the mission to provide innovative solutions for the leading health problems in America and globally-from infectious and chronic diseases to health care financing and health systems. The Institute, a joint project of the Law Center and School of Nursing and Health Studies, also draws upon the University's considerable intellectual resources, including the School of Medicine, the Public Policy Institute, and the Kennedy Institute of Ethics.

The essential vision for the O'Neill Institute rests upon the proposition that the law has been, and will remain, a fundamental tool for solving critical health problems in our global, national, and local communities. By contributing to a more powerful and deeper understanding of the multiple ways in which law can be used to improve health, the O'Neill Institute hopes to advance scholarship, research, and teaching that will encourage key decisionmakers in the public, private, and civil society sectors to employ the law as a positive tool for enabling more people in the United States and throughout the world to lead healthier lives.

- Teaching. Georgetown is educating future generations of students who will become - upon their graduation - policymakers, health professionals, business leaders, scholars, attorneys, physicians, nurses, scientists, diplomats, judges, chief executive officers, and leaders in many other private, public, and nonprofit fields of endeavor. The O'Neill Institute helps to prepare graduates to engage in multidisciplinary conversations about national and global health care law and policy and to rigorously analyze the theoretical, philosophical, political, cultural, economic, scientific, and ethical bases for understanding and addressing health problems.

- Scholarship. O'Neill supports world-class research that is applied to urgent health problems, using a complex, comprehensive, interdisciplinary, and transnational approach to go beyond a narrow vision of health law that focuses solely on health care as an industry or as a scientific endeavor.

- Reflective Problem-Solving. For select high-priority issues, the O'Neill Institute organizes reflective problem-solving initiatives in which the Institute seeks to bridge the gap between key policymakers in the public, private, and civil society sectors and the intellectual talent and knowledge that resides in academia.

O’NEILL INSTITUTE FOR NATIONAL AND GLOBAL HEALTH LAW 


\section{OVERVIEW \\ LEGAL SOLUTIONS IN HEALTH REFORM}

The American public has increasingly identified health care as a key issue of concern. In order to address the multiple problems relating to the access and affordability of health care, President Obama and federal lawmakers across the political spectrum continue to call for major health reform. In any debate on health reform, a predictable set of complex policy, management, economic, and legal issues is likely to be raised. Due to the diverse interests involved, these issues could lead to a series of high-stakes policy debates. Therefore, it is critical that advocates of reform strategies anticipate such issues in order to decrease the likelihood that legally resolvable questions become barriers to substantive health reform. In an effort to frame and study legal challenges and solutions in advance of the heat of political debate, the O’Neill Institute for National and Global Health Law at Georgetown University and the Robert Wood Johnson Foundation have crafted the "Legal Solutions in Health Reform” project.

This project aims to identify practical, workable solutions to the kinds of legal issues that may arise in any upcoming federal health reform debate. While other academic and research organizations are exploring important policy, management, and economic questions relating to health reform, the O'Neill Institute has focused solely on the critical legal issues relating to federal health reform. The target audience includes elected officials and their staff, attorneys who work in key executive and legislative branch agencies, private industry lawyers, academic institutions, and other key players. This project attempts to pave the road towards improved health care for the nation by providing stakeholders a concise analysis of the complex legal issues relating to health reform, and a clear articulation of the range of solutions available.

\section{Legal Issues V. Policy Issues}

Among the major issues in federal health reform, there are recurring questions that are policybased and those that are legally-based. Many times questions of policy and of law overlap and cannot be considered in isolation. However, for the purpose of this project, we draw the distinction between law and policy based on the presence of clear legal permission or prohibition.

Under this distinction, policy issues include larger-scale questions such as what basic model of health reform to use, as well as more technical questions such as what threshold to use for poverty level subsidies and cost-sharing for preventive services. In contrast, legal issues are those involving constitutional, statutory, or regulatory questions such as whether the Constitution allows a certain congressional action or whether particular laws run parallel or conflict.

Based on this dividing line of clear permission or prohibition, policy questions can be framed as those beginning with, "Should we...?", and legal questions can be framed as those beginning with, "Can we...?" The focus of this paper will be the latter, broken into three particular categories: 1) "Under the Constitution, can we ever...?”; 2) "Under current statutes and regulations, can we now...?”; 3) “ Under the current regulatory scheme, how do we...?” This final set of questions tends to be mixed questions of policy, law, and good legislative drafting.

\section{Purpose and Layout of The Project}

O’NEILL INSTITUTE FOR NATIONAL AND GLOBAL HEALTH LAW

GEORGETOWN LAW | 600 NEW JERSEY AVENUE NW | WASHINGTON, DC 20001 www.oneillinstitute.org 
This project is an effort to frame and study legal challenges and solutions in advance of the heat of political debate. This effort is undertaken with the optimistic view that all legal problems addressed are either soluble or avoidable. Rather than setting up roadblocks, this project is a constructive activity, attempting to pave the road towards improved health care for the nation. Consequently, it does not attempt to create consensus solutions for the identified problems nor is it an attempt to provide a unified field theory of how to provide health insurance in America. Furthermore, this project does not attempt to choose among the currently competing proposals or make recommendations among them. Instead, it is a comprehensive project written to provide policy makers, attorneys, and other key stakeholders with a concise analysis of the complex legal issues relating to health reform and a clear articulation of the range of solutions available for resolving those questions.

\section{LEGAL ISSUES}

Based on surveys of current health policy meetings and agendas, popular and professional press, and current health reform proposals, our team formulated a list of legal issues relating to federal health reform. After much research, discussion, and expert advice and review, our initial list of over 50 legal issues was narrowed to ten. An initial framing paper was drafted which identified these ten legal issues and briefly outlined the main components of each. In May of 2008, a bipartisan consultation session was convened to provide concrete feedback on the choice and framing of the legal issues. The attendees of the consultation session included congressional staff, executive branch officials, advocates, attorneys, employers, and representatives of a wide range of interests affected by health reform. Feedback and analysis from this session further narrowed the ten issues to eight key legal issues which warranted in depth analysis of the current law.

These eight pertinent issues are truly legal in nature and must be addressed in any significant reform proposal to avoid needless debate or pitfalls as policy decisions are made. There are multiple other legal issues that will arise as the discussion evolves and, if a federal policy is adopted, the system changes. In this project, however, we have targeted the issues essential for an immediate discussion of federal health reform. 


\section{O’Neill Institute}

for National and Global Health Law

\section{LEgAL Solutions IN HEALTh REFoRM PROJECT}

JOHN T. MONAHAN, JD

Research Professor

Georgetown Health Policy Institute

Co-Director

Legal Solutions in Health Reform

JACQUELINE R. SCOTT, JD, ML

Adjunct Professor, Senior Fellow

Harrison Institute for Public Law

Georgetown Law

BENJAMIN E. BERKMAN, JD, MPH

Former Deputy Director \& Adjunct Professor

O’Neill Institute

Georgetown Law

\section{SHEILA P. BURKe, MPA, RN}

Research Professor

Georgetown Public Policy Institute

Distinguished Visitor, O’Neill Institute

Adjunct Lecturer and Senior Faculty Research

Fellow, Harvard University

John F. Kennedy School of Government

LisBeTH A. ZEgGANE

Former RWJF Project Assistant

O'Neill Institute
TIMOTHY M. WESTMORELAND, JD

Visiting Professor of Law

Georgetown Law

Co-Director

Legal Solutions in Health Reform

SARA P. HoverTer, JD, LLM

Staff Attorney, Adjunct Professor

Harrison Institute for Public Law

Georgetown Law

JACK EBELER, MPA

Distinguished Visitor, O’Neill Institute

Ebeler Consulting

SANDY H. HAN, JD, LLM

Teaching Fellow

Harrison Institute for Public Law

Georgetown Law

ELENORA E. CONNORS, JD, MPH

Fellow

O’Neill Institute

Georgetown Law

Mariesa M. Martin

RWJF Project Assistant

O'Neill Institute

Special thanks to the following individuals who contributed to the editing and production of the Legal Solutions in Health Reform Series, as well as the drafting of the Executive Summaries: Brian Bowen, Astrid Dorélien, Marissa Hornsby, Amy Killelea, Melanie MacLean, Anya Prince, and Luis Rodriguez. Also special thanks to John Kraemer for editing and production assistance. 


\section{LEGAL SOLUTIONS IN HEALTH REFORM \\ LEAD AUTHORS}

Executive Authority

Madhu Chugh, JD, MPP

Law Clerk

U.S. Court of Appeals for the D.C. Circuit

Washington, D.C.

Tax Credits for Health

Fred T. Goldberg, Jr., Esq.

Partner

Skadden, Arps, Slate, Meagher \& Flom, LLP

Washington, D.C.

\section{Insurance Exchanges}

Timothy S. Jost, JD

Robert L. Willet Family Professorship of Law

Washington \& Lee School of Law

Lexington, V.A.

Privacy and Security of Information

Deven McGraw, JD, LLM, MPH

Director, Health Privacy Project

Center for Democracy \& Technology

Washington, D.C.
Individual Mandates

Mark A. Hall, JD

Fred D. \& Elizabeth Turnpage

Professor of Law

Wake Forest University School of Law

Winston-Salem, N.C.

\section{ERISA}

Peter D. Jacobson, JD, MPH

Professor of Health Law \& Policy

Director, Center for Law, Ethics, and Health University of Michigan

School of Public Health

Ann Arbor, M.I.

Purchase of Insurance Across State Lines Stephanie Kanwit, JD

Special Counsel \& Healthcare Consultant America's Health Insurance Plans

Washington, D.C.

Insurance Discrimination Based on Health Status

Sara Rosenbaum, JD

Harold and Jane Hirsh Professor of Health

Law \& Policy

Chair, Department of Health Policy

The George Washington University School

of Public Health and Health Services

Washington, D.C. 


\section{About THE AUthor}

Sara Rosenbaum, J.D., is the Harold and Jane Hirsh Professor and founding Chair of the Department of Health Policy at the George Washington University School of Public Health and Health Services, a unique center of learning, scholarship, and service focusing on all aspects of health policy.

Professor Rosenbaum has devoted her career to issues of health law and policy affecting low income, minority, and medically underserved populations as well as the health care safety net. Between 1993 and 1994, Professor Rosenbaum worked for President Clinton, directing the legislative drafting of the Health Security Act and developing the Vaccines for Children program. Professor Rosenbaum also served on the Presidential Transition Team for PresidentElect Obama.

A graduate of Wesleyan University and Boston University School of Law, Professor Rosenbaum has authored more than 250 articles and studies focusing on all phases of health law and health care for medically underserved populations. She is co-author of Law and the American Health Care System (Foundation Press, NY) and has won many national awards for her scholarship and service including the Richard and Barbara Hansen National Health Leadership Award (University of Iowa), a Robert Wood Johnson Foundation Investigator Award in Health Policy Research, and the Oscar and Shoshanna Trachtenberg Award for Scholarship, the George Washington University's highest faculty award. 


\section{EXECUTIVE SUMMARY \\ Prepared by the O'Neill Institute}

\section{INTRODUCTION:}

Actuarial underwriting or discrimination based on an individual's health status is a business feature of the voluntary private insurance market. The term "discrimination" in this paper is not intended to convey the concept of unfair treatment, but rather how the insurance industry differentiates among individuals in designing and administering health insurance and employee health benefit products. Discrimination can occur at the point of enrollment, coverage design, or decisions regarding scope of coverage. Several major federal laws aimed at regulating insurance discrimination based on health status focus at the point of enrollment. However, because of multiple exceptions and loopholes, these laws offer relatively limited protections. This paper provides a brief overview of discrimination practices, the federal law, and federal reform options to manage discriminatory practices in the insurance and employee health benefit markets.

\section{POTENTIAL SOLUTIONS:}

\section{Long-Term Solutions}

- Establish a nationwide group purchasing mechanism in which all residents could automatically be enrolled with opt-out provisions for those covered through employer-sponsored plans or with coverage through public programs such as Medicaid.

- Require entities that sell health benefits products to meet minimum coverage standards such as a benefit design modeled after the Federal Employee Health Benefit Plan. Allow broader coverage through an exceptions process similar to that used in Medicare Part D in the case of individuals who need benefits different from or greater than that specified in the plan design and who can provide medical evidence to support the claim.

- Require payment plans to take into account the higher level of care associated with treating individuals with complex underlying medical conditions and thereby avoid the refusal to treat more complex patients.

- Amend Medicaid to create more explicit standards regarding provider payment levels.

- Revise Medicaid to create coverage for benefits that are necessary to treat and manage serious and chronic health conditions whose treatment requires services and benefits not covered through the nationwide group purchasing pool. In this way, people who receive standard coverage through the pool could still obtain supplemental coverage for serious and chronic conditions through Medicaid.

\section{Interim Solutions}

\section{Amend or Expand Existing Federal Laws}

- Expand HIPAA's prohibition on pre-existing condition exclusions to apply to all persons seeking coverage, not just those with requisite "creditable coverage."

- Enact legislation to subsidize COBRA benefits and enable people to remain in an employer group.

- Expand Medicaid to any child or adult unable to obtain coverage through the individual market.

Expand Protections through Agency Regulations or Interpretation

- Impose limits on the extent to which insurers and plans can impose treatment limits that differentiate between covered physical and mental health conditions.

- Rigorously oversee state compliance with HIPAA's non-discrimination and guaranteed issue requirements.

O’NEILL INSTITUTE FOR NATIONAL AND GLOBAL HEALTH LAW 


\section{RELEVANT LAW:}

The following federal laws focus on addressing discrimination based on health status that occurs at the point of enrollment, but only tackle risk management techniques linked to coverage to a limited degree.

- Title VII of the 1964 Civil Rights Act prohibits intentional and disparate impact discrimination in the form of lesser benefits based on race; and prohibits both greater charges and provision of lesser-value benefits based on sex.

- Age Discrimination in Employment Act (ADEA) permits employers to offer older workers lesser health benefits through the use of an "equal benefit or equal cost" test.

- Americans with Disabilities Act (ADA) and Section 504 of the Rehabilitation Act of 1973 prevent any employer-sponsored plan or public insurance program operating in either the group or individual market from refusing to enroll a qualified person with a disability. Title II of the ADA and Section 504 cover public and federally-assisted programs, but protections are limited to access to any coverage, rather than the quality of coverage. As long as limitations on coverage are applied to all recipients, despite the fact that such limitations have a disproportionate impact on people with disabilities, they are upheld. ADA contains an "insurance safe harbor" that protects risk classification as permissible activity and means that the ADA does not reach the content of insurance.

- Health Insurance Portability and Accessibility Act (HIPAA) prohibits application of preexisting condition exclusions in group health insurance as long as the individual has had at least 18 months of creditable coverage. But coverage design, as long as applied uniformly, can contain specific limitations and exclusions. HIPAA allows employers or insurers to offer premium discounts or modified cost sharing in exchange for participation in a bona fide wellness program.

- Genetic Information Non-discrimination Act (GINA) prohibits employee health benefit plans and insurers in both the group and individual markets from using genetic information to determine the level of premiums to be charged.

- Mental Health Parity and Addiction Equity Act applies to plans and products that cover mental health or substance abuse disorder benefits and requires parity in financial requirements (deductibles, copayments, and coinsurance) and treatment limitations (limits on number of visits and days of coverage) for mental and physical illness.

- Newborns and Mothers Protection Act requires plans that offer hospital stays in connection with childbirth to provide a minimum stay following delivery.

- Women's Health and Cancer Rights Act (WHCRA) applies to group health plans that provide mastectomy benefits and requires plans to cover breast reconstruction, prostheses, and other treatments addressing complications of a mastectomy.

- Employee Retirement Income Security Act (ERISA) establishes "full and fair hearing" provisions and standards for timeliness and conduct of internal appeals of health benefit denials.

\section{CONCLUSION:}

Congress has limited the use of actuarial techniques that exclude persons from group insurance altogether. However, Congress has only modestly tackled risk management techniques linked to the actual content and administration of coverage. The use of discriminatory practices based on health status to limit coverage is especially apparent in the individual insurance market. If the federal government wishes to move in the direction of sharing health risks more broadly, next steps will include creating larger risk-pooling groups and curbing the ability of insurers to limit adequate coverage based on health status.

O’NEILl INSTITUTE FOR NATIONAL AND GLOBAL HEALTH LAW 


\section{Legal Solutions in Health Reform: \\ Insurance Discrimination on the Basis of Health Status: \\ An Overview of Discrimination Practices, Federal Law and Federal Reform Options \\ Sara Rosenbaum ${ }^{\mathrm{a}}$}

\section{Introduction}

This is an important time to focus on the question of insurance discrimination based on health status. The nation once again is poised to embark on a major health care reform debate; even as the number of uninsured stands at some 45 million persons, millions more may be poised to lose coverage during the worst economic downturn in generations. In addition, a large number of persons may be seriously under-insured, with coverage falling significantly below the cost of necessary health care. In recent years, the proportion of insured persons who are underinsured has grown by $60 \%$ since 2003, reaching an estimated 25 million persons in 2007. ${ }^{1}$ Health care costs experienced by insured persons now account for more than $75 \%$ of all personal bankruptcies related to medical care. ${ }^{2}$ Underlying these figures is a national approach to health care financing for the non-elderly that effectively increases the odds that those who are in poor health status will be uninsured or underinsured. ${ }^{3}$ Why this is so, and what to do about it, is the subject of this analysis, made timely by recent signals of openness on the part of the health insurance industry to address the problem of discrimination based on health status in exchange for universal and compulsory enrollment. ${ }^{4}$

This paper, prepared for Legal Solutions in Health Reform, examines insurance discrimination based on health status. As used in this analysis, the term "discrimination" is not intended to convey the concept of unfair treatment ${ }^{5}$; instead the term is intended to convey how society differentiates among the population in exposing individuals to financial risks associated with health care. In the U.S., which has built its approach to health care financing largely according to market principles, the challenges to managing the system's potential to discriminate against the sick are especially notable calling for incremental reforms that retain markets while introducing innovations into how financial risks are managed, not only at the entry point into enrollment, but also in how coverage itself is defined, structured and administered. The extent to which this differentiation is permitted - not only at the point of enrollment into coverage but also in relation to the design and administration of coverage - carries important implications for the nation's ability to ensure health care efficiency and equity. To the extent that the American health care financing system is enabled - and indeed incentivized - to exclude the sick, ${ }^{6}$ the consequences extend beyond the ethical or moral. Indeed, the consequences of discrimination in financing implicate the ultimate goal of any nation's health care system, best summed up by the Institute of Medicine: safe, effective, patient-centered, timely, efficient, and equitable. ${ }^{7}$ All Americans, regardless of health status at any point in time, have a stake in how health care financing treats people in poorer health.

This analysis begins with an overview of "actuarial fairness" and "social solidarity," two concepts that represent opposing endpoints along the spectrum of possible approaches to the allocation of financial risk for health care across a population. The overview also discusses the tools used by insurers to shield themselves against persons with higher health risks. Depending on where a particular health care financing system falls along this broad conceptual spectrum,

O’NEILl INSTITUTE FOR NATIONAL AND GLOBAL HEALTH LAW

GEORGETOWN LAW | 600 NEW JERSEY AVENUE NW | WASHINGTON, DC 20001 www.oneillinstitute.org 
devising legal solutions to the problem of health status discrimination will pose a greater or lesser challenge.

Following this overview, the analysis discusses a series of federal laws relevant to the issue of insurance discrimination based on health status. These laws fall along various points of the antidiscrimination policy spectrum, and offer relatively limited protections against discriminatory practices. For example, group health benefit plans sponsored by state and local governments are exempt from laws regulating discrimination in private employer sponsored group health plans. ${ }^{8}$ In addition, separate laws apply to coverage arrangements purchased by government sponsors such as Medicare and Medicaid, and a distinct body of law governs state-regulated health insurance sold in the individual insurance market.

The paper also considers Medicaid's continuing role in a reformed health care financing system. Medicaid-purchased coverage deserves special consideration because Medicaid's enrollment and coverage features are related to its central purpose of covering individuals whose poor health and medical impoverishment virtually exclude them from the private health insurance market. ${ }^{9}$ In contrast to insurance markets, Medicaid coverage is available at the very point that serious health need arises. The law contains no eligibility exclusions for pre-existing conditions; ${ }^{10}$ many of its numerous eligibility categories are expressly designed to deal with coverage during illness; ${ }^{11}$ and states are required to provide for enrollment services in health care settings ${ }^{12}$ in order to enable enrollment at the point of health care need. Medicaid coverage similarly is governed by principles of reasonableness that to a large degree bar the health status-based coverage distinctions that are a hallmark of private health insurance, in particular, the complete exclusion of certain health conditions from coverage. ${ }^{13}$ How Medicaid might be reconfigured in a health care system in which discrimination based on health status is mitigated will be discussed at greater length.

The analysis concludes with a discussion of legal solutions to discrimination that focus on reforms aimed at preserving health insurance markets while limiting discrimination, in order to align health care financing more closely with the basic goals of a high performing health care system. As described more thoroughly below, the individual market presumably would disappear under legal reforms proposed here, since the establishment of group purchasing arrangements can be a foundational legal step in mitigating discrimination.

\section{The Conceptual Starting Point: Defining the Concepts and Describing the Tools of Insurance Discrimination Based on Health Status}

Understanding insurance discrimination based on health status requires grounding in three sets of concepts. The first is the concept of pooling: the assemblage of members into a group.

The second set of concepts is found along the spectrum of strategic approaches to assigning risk within the pool. At one end lies the concept of actuarial fairness (sometimes known as fair discrimination); ${ }^{14}$ and at the other end, the concept of social solidarity. Each concept represents a seminal vantage point from which to assess, manage and allocate costs associated with the financial risk of health care utilization by members of the pooled group.

The third concept, which will be termed in this analysis as "discrimination tools," is the mechanisms by which discrimination is accomplished by the health benefit services companies

\footnotetext{
O’NEILl INSTITUTE FOR NATIONAL AND GLOBAL HEALTH LAW GEORGETOWN LAW | 600 NEW JERSEY AVENUE NW | WASHINGTON, DC 20001 www.oneillinstitute.org
} 
that either assume risk through the sale of insurance products or manage risk for self insured group sponsors.

\section{A. Risk Pooling}

Tom Baker and Jonathan Simon, two of the nation's leading experts in insurance law and theory, have written that insurance is the "paradigmatic risk spreading institution." 15 This act of risk spreading can occur in various ways. At one end of the spectrum, the risks associated with poor health can be spread across an entire society. For example, enrollment in the risk pool could be automatic for all U.S. residents, much in the way that working at a Social Security-insured job automatically leads to enrollment in the Social Security system. Coverage could be financed through broad-based tax mechanisms as the financing mechanism. European nations commonly rely on this social approach to achieving and maintaining coverage, ${ }^{16}$ and the Medicare program also possesses these characteristics.

Alternatively, risks can be spread among small - voluntarily selected and selecting - groups. This is the case with private employer coverage, particularly coverage offered to small groups. (In truth, of course, even a large group employer is a small group when compared to society as a whole). In this voluntary system, employers elect to offer coverage, ${ }^{17}$ employees elect to buy coverage for themselves and their families, ${ }^{18}$ and insurers elect to sell either insured or administered products in certain employer markets. For example, some health benefit services companies may choose to sell small group insurance products in only certain states or may eschew the small group market entirely in favor of the non-risk administered products associated with larger employer groups.

\section{B. Social Solidarity Versus Actuarial Fairness.}

How might the risk of loss be spread across a group? Two concepts that lie at opposite ends of the risk spreading spectrum present two distinctly different ways to think about the act of spreading risk. At one end is the "social solidarity"19 approach, which in its purest form spreads the cost of coverage equally across the entire group, a practice that is known as "community rating." 20 This practice subjects all to the same access to insurance, coverage rules and rates. Critics argue that under this practice, some, such as younger individuals with lower health risks, subsidize older individuals, which may keep them from signing up for the coverage itself.

At the other end of the spectrum is what Baker and Simon call the "actuarial vision" of risk. ${ }^{21}$ In this model, which goes by the name "actuarial fairness," actuarial science techniques are used to classify individuals by specific characteristics that in turn are associated with the use of care (health care experience) and thus, with the risk of financial loss to an insurer (known as medical loss). Thus, underwriting is used to evaluate the risks posed by particular individuals and to adjust enrollment rules and premiums accordingly. ${ }^{22}$ Some individuals may be considered too big a risk to be permitted to enroll either at all, or without certain conditions, such as pre-existing condition exclusions designed to shield the group from health conditions present at the time of enrollment. Other individuals may be allowed in, but charged disproportionately high premiums. $^{23}$

Risk shielding continues across the continuum of the insurance enterprise. Thus, the insurer may design the benefit product to avoid certain types of conditions and treatments - particularly those

\footnotetext{
O’NEILl INSTITUTE FOR NATIONAL AND GLOBAL HEALTH LAW

GEORGETOWN LAW | 600 NEW JERSEY AVENUE NW | WASHINGTON, DC 20001 www.oneillinstitute.org
} 
that are costly and chronic - through the use of coverage limitations and exclusions. High cost sharing may be imposed selectively. Thus, the shielding process begins at the point of entry and proceeds throughout the terms of coverage.

The concept of actuarial fairness and its resulting underwriting techniques can produce perverse results, particularly when classification of individual risk is based on immutable characteristics such as race, national origin, or sex. For example, African Americans historically have been subjected to exclusions and higher premiums because of higher associated health costs, ${ }^{24}$ therefore the use of tools to shield against risks posed by racial and ethnic minority members may be continuing. ${ }^{25}$ Similarly, women traditionally are charged higher health insurance premiums than men, because actuarial data tend to show that their health status and health care needs, at least during certain periods of their lives, may drive higher utilization rates. ${ }^{26}$

\section{Specific Risk Shielding Tools}

Because Americans tend to pool in small groups (again, even a large employer is a small group when compared to society as a whole), there are relatively few persons over whom a health benefit services company can spread the financial risks associated with the use of health care. In this regard, two types of health care costs must be considered: macro-level costs and micro-level costs. Both types of costs affect the risk of loss, and for this reason, avoiding the financial losses associated with macro- and micro-level costs becomes part of the business of insurance. ${ }^{27}$ Scores of judicial decisions that consider the "business of insurance" in the context of ERISA preemption underscore the broad range of design and management tools available to insurers and plan administrators to manage plans from financial risk. ${ }^{28}$

Macro-level costs are associated with coverage design, that is, the benefits, limitations and exclusions, coverage definitions, deductible and cost sharing requirements, and the other terms of coverage that are embedded in the terms of coverage that apply to the group and determine the scope of coverage that potentially will be made available to any member of the group. Macro limits come in many shapes and forms. And focus on what classes of benefits to cover; whether the terms of coverage apply to treatments for certain conditions such as mental illness ${ }^{29}$ or HIV/AIDS; ${ }^{30}$ whether the coverage terms extend speech therapy only for persons who once spoke and have lost speech as the result of a stroke or extend coverage to children whose inability to speech is connected with conditions present at birth; ${ }^{31}$ or whether certain classes of benefits will be included in a prescription drug formulary, and if not, whether to permit participants to seek an exception from the coverage restriction. ${ }^{32}$ If the terms of coverage expressly encompass conditions and treatments or at least do not exclude them, then these services become potentially available to members of the group and must be assigned an actuarial value. This is because the very presence of covered items and services in the coverage agreement is characterized as creating a "moral hazard" (i.e., increasing the likelihood that insured persons will use the coverage potentially available to them). ${ }^{33}$ In this model, the need for health care essentially becomes the result of individual choice rather than health status (which by contrast is understood as the product of inherent traits, social environment, and behavior, which itself is shaped by the broader social environment). ${ }^{34}$

The second group of financial risks associated with the cost of health care consists of costs at the micro level of coverage, that is, at the level at which costs are actually incurred because a member is attempting to use benefits. Thus, if a health insurance contract covers speech therapy,

O’NEILl INSTITUTE FOR NATIONAL AND GLOBAL HEALTH LAW

GEORGETOWN LAW | 600 NEW JERSEY AVENUE NW | WASHINGTON, DC 20001 www.oneillinstitute.org 
treatments for mental illness and treatment for AIDS, the actual cost of care transpires when a particular patient makes use of the coverage in the receipt of care. Thus, how an insurer conducts medical necessity reviews and whether an external appeal is allowed becomes a matter of financial risk to the group. $^{35}$ In a similar vein, whether to offer a broad provider network ${ }^{36}$ and whether and how to pay out-of-network providers in particular cases ${ }^{37}$ in turn will affect the level of financial risk to which an insurer is exposed, as well as the actuarial estimates related to costs and pricing.

In sum, both macro- and micro- level risks are relevant when thinking about risk shielding tools. Certain risk shields happen at the preliminary enrollment phase while others occur throughout the coverage and management phases of the insurance enterprise. And the tools have an interactive relationship with one another. For example, barring insurers from excluding people in poorer health status or putting conditions on their enrollment will in turn affect the level of financial risk to which the insurer is exposed. This fact will trigger the need for more back-end risk-shielding tools as part of coverage and management, including tools linked to benefit coverage design, cost sharing, and plan administration. Indeed, the more that people in poor health are admitted into a pool without front-end restrictions, the greater the need for back-end risk shielding techniques (e.g., limitations on coverage and plan administration).

Even before one gets to enrollment and coverage risk shields, a voluntary employment based system offers a number of relatively obvious ways to discriminate against poor health risks, such as marketing only to large employed groups or healthy smaller groups, a technique that offers companies the advantage of larger numbers and/or a relatively healthy self-selected group. Another obvious strategy is to use fixed, open enrollment periods in order to guard against adverse selection by eligible individuals who otherwise might seek to enroll only at the point of health care need.

But these two threshold strategies have their limitations. Even healthy workers can become sick, and certain qualifying events, such as divorce may trigger special enrollment periods at firms. Thus, companies must use back-end techniques linked to coverage itself in order to shield against health risks. These risk shielding techniques can be clustered into two principal domains. The first domain is linked to membership in the group, that is, the ability to enroll and to do so without exclusionary terms to screen out pre-existing conditions, and at an affordable cost. This domain encompasses several sub-domains: who is eligible to enroll, the restrictions that might be placed on enrollment, and the price that must be paid for membership in the group.

The second domain consists of post-enrollment coverage techniques used to avoid financial risks associated with the use of health care services. This domain likewise encompasses a series of sub-domains: benefit classes, service and treatment exclusions; contractual definitional terms; cost sharing including deductibles, copayments, coinsurance, and payment maximums; provider network design, payment terms, and other structural considerations; and matters of plan administration such as utilization review, and a rapid and transparent appeals process.

Again, these enrollment and coverage domains are highly interactive. That is, they work together in various ways and are influenced by one another. For this reason, regulations aimed at one domain, such as barring the use of pre-existing condition exclusions, can be expected to have spillover effects in the form of more aggressive coverage design and plan administration techniques. Indeed, it is worth observing that the market interest in high deductible health plans

O’NEILl INSTITUTE FOR NATIONAL AND GLOBAL HEALTH LAW GEORGETOWN LAW | 600 NEW JERSEY AVENUE NW | WASHINGTON, DC 20001 www.oneillinstitute.org 
offering limited coverage coincided with the enactment of federal and state laws in the latter half of the 1990s prohibiting enrollment discrimination, ${ }^{38}$ along with the provider and consumer backlash against managed care.

\section{Enrollment-linked Tools}

The threshold strategy for health status discrimination is the avoidance of risk altogether by barring, preventing, or effectively constraining enrollment. As will be reviewed below, these techniques have received a somewhat greater level of attention in insurance reform laws enacted in recent years.

- Barring enrollment by refusing to issue a product. An insurer might bar enrollment outright based on health status alone. This type of absolute enrollment bar is a principal characteristic of the individual insurance market.

- Medical underwriting to classify risks and adjust premiums. An insurer might use medical underwriting techniques to group risks by personal characteristics that could be expected to affect use of care. Risk classification would permit the adjustment of premiums to reflect the level of financial risk perceived to be involved. Individuals whose characteristics (both health status and personal characteristics that predict health status and insurance use) pose higher financial risks thus would be expected to pay a higher premium, and in some cases perhaps sufficiently high enough to render coverage unaffordable.

- The use of pre-existing condition exclusions and waiting periods. An insurer might permit enrollment while imposing total exclusions for pre-existing conditions or waiting periods of modest to moderate length. This would offer further protection against the assumption of risk by placing constraints on enrollment rather than barring enrollment altogether.

- Coverage rescissions and cancellations. Assuming that an individual is permitted to enroll, an insurer might cancel coverage in an ensuing benefit period or revoke coverage during the plan year in the event that the individual's use of resources exceeds anticipated norms, and the insurer suspects the existence of fraud at the point of enrollment

\section{Post-enrollment Coverage and Plan Administration Risk Shielding Tools}

Assuming that enrollment occurs, a second issue arises, namely, how to manage risks associated with coverage and utilization of health care. Several basic strategies exist: limiting the scope of coverage; high cost sharing; utilization management techniques and constraining challenges to coverage denials; and constraining the size and operation of provider networks and provider payment.

- Limits on the amount, duration, or scope of coverage. Contractual limits on the amount, duration and scope of coverage (e.g., the classes of benefits offered, how covered benefit classes are defined, and the conditioning of coverage on certain applicable requirements) work to minimize the financial risks associated with coverage. For example, coverage of speech therapy to "restore speech" automatically excludes coverage for children born

O’NEILL INSTITUTE FOR NATIONAL AND GLOBAL HEALTH LAW

GEORGETOWN LAW | 600 NEW JERSEY AVENUE NW | WASHINGTON, DC 20001 www.oneillinstitute.org 
with a developmental disability who need therapy to attain speech. ${ }^{39}$ Certain treatments for mental disorders or for HIV/AIDS could be radically limited or altogether excluded. ${ }^{40}$ Similarly, embedded and undisclosed practice guidelines that limit available treatments for mental illness or addiction ${ }^{41}$ would shield risk by considerably narrowing the scope of an apparently covered benefit class for certain specified conditions. Along the same lines, a medical necessity standard that defines treatment as necessary only when restoration of previous functioning is possible automatically eliminates the potential for covering treatments whose medical purpose is to help a patient attain, maintain, or avert the loss of functioning. ${ }^{42}$

- Cost sharing. Insurers have a range of cost-sharing options, including across-the-board or condition- or treatment-specific deductibles, copayments and coinsurance. Costsharing can involve both covered services furnished by in-network providers as well as balance billing by out-of-network providers in the case of network plans. ${ }^{43}$ Plans might tier network cost sharing in order to use economic incentives (in the form of higher deductibles or copayments) to steer patients toward providers that are shown to be more "efficient" in their use of plan resources or that have offered a plan additional discounts. $^{44}$ Similarly, insurers might impose annual or lifetime dollar limits on care either generally or by condition. ${ }^{45}$

- Utilization management and procedures for challenging coverage denials. Insurers can use the case-by-case utilization review process to limit their risk exposure, drafting contracts so that they retain broad discretion over whether to approve coverage at all or to impose limitations on coverage (e.g., "in our discretion," or "as determined by us"). ${ }^{46}$ This discretion can extend to the power to determine the evidence that will be considered relevant ${ }^{47}$ along with the power to define an appeals process that favors the insurer. ${ }^{48}$ Ultimately, because the burden of proof lies with the challenger in a coverage denial, ${ }^{49}$ participants and beneficiaries may face an uphill fight.

- Network size, composition and payment. Network size matters in calculating financial risk. $^{50}$ For this reason, limiting primary or specialty network size and composition affects utilization. It also potentially deters product selection by individuals with serious and chronic conditions who fear limitations on their access to in-network providers. ${ }^{51}$ Tiering provider networks based on performance or price offers an additional technique for shielding a company against risk. ${ }^{52}$ Similarly, restricting the scope of payable procedures and items within any covered benefit class and paying lower rates for certain covered services both help shield risk by constraining the flow of resources. This practice may also have the effect of incentivizing providers to abandon network membership so that they can treat patients on an "out-of-network" basis and balance bill for their care.

It is important again to stress the interdependent nature of these techniques. For example, regulations that limit the use of enrollment-related risk management tools can be expected to result in the use of higher deductibles and cost sharing, more tightly circumscribed coverage terms, more aggressive use of embedded practice guidelines, stricter utilization review in the case of high cost procedures, a more tightly controlled appeals system, and more restrictive networks with lower payments.

O’NEILL INSTITUTE FOR NATIONAL AND GLOBAL HEALTH LAW GeORgETOWN LAW | 600 NEW JERSEY AVENUE NW | WASHINGTON, DC 20001 www.oneillinstitute.org 


\section{Federal Efforts to Regulate Insurance Discrimination Based on Health Status}

Four major bodies of federal law regulate discrimination by health benefit service companies based on health status: civil rights laws; tax law; labor law; and laws that finance state public health activities. Although federal laws that protect against insurance discrimination date back to the 1964 Civil Rights Act, Congress has shown a growing interest in recent years to make additional inroads on the issue of insurance discrimination based on health status. At the same time, the materials that follow underscore the limited nature of these more recent laws.

\section{A. Civil Rights Law}

Race. Most states outlaw the use of race-based classifications either directly or as a subset of prohibited unfair trade practices acts. ${ }^{53}$ But such a regulatory approach tends to be confined to laws that reach intentional discrimination and exclusion, not the disparate effects that stem from the facially neutral use of certain risk classifications. ${ }^{54}$ Title VII of the 1964 Civil Rights Act, which reaches discrimination in both employment and the conditions of employment (including fringe benefits), ${ }^{55}$ prohibits discrimination on the basis of race, sex, or national origin and bars both intentional and disparate impact discrimination (i.e., unintentional discrimination). ${ }^{56}$ Thus Title VII would be implicated in situations in which protected groups of individuals are exposed to less effective benefits as a result of risk classification. ${ }^{57}$ In addition, Title VI of the 1964 Civil Rights Act, which bars discrimination in federally assisted activities, ${ }^{58}$ has been interpreted as prohibiting public insurance administration practices that result in racially segregated health care. $^{59}$ In addition, legislation implementing the Civil War Amendments has been interpreted as prohibiting the use of race as a classifier in private insurance contracts. ${ }^{60}$

It may well be that the basis for the prohibition against the use of race as a classifier is not that race is not relevant to health risk; indeed, from an actuarial perspective, as in health services research, race may be significantly associated with poor health. Instead, the prohibition appears to arise from the fact that a democratic society simply does not allow racial and ethnic minority individuals to be classified as poor risks and denied the benefits of insurance based on their immutable characteristics. ${ }^{61}$ In this sense, the rejection of race as a permissible risk classifier for purposes of enrollment or coverage represents perhaps the purest example of the trumping of actuarial fairness by social solidarity.

$\underline{\text { Sex. }}$ Less consensus exists where risk classification based on sex is concerned. State laws clearly continue to permit risk classification in insurance. ${ }^{62}$ Thus, prohibitions on the use of gender in risk classification vary both by employment and non-employment status and by state versus federal law. ${ }^{63}$ Where employment-based coverage is concerned, Title VII appears to produce a more unified response, because it has been interpreted to bar both greater charges for one sex, as well as lesser-value benefits based on sex. ${ }^{64}$ As one observer has written, the standard of review is "not confined to asking whether male and female employees receive the same policy with identical terms; it instead compares how thoroughly that policy actually covers male and female enrollees' medical expenses." ${ }^{65}$ Title VII also prohibits discrimination based on "pregnancy, childbirth, or related medical conditions.",66

Age. The Age Discrimination in Employment Act (ADEA) offers only "meager"67 protection against discrimination in employee health benefits, since the Act explicitly permits employers to offer older workers lesser health benefits through the use of an "equal benefit or equal cost"

O’NEILl INSTITUTE FOR NATIONAL AND GLOBAL HEALTH LAW

GEORGETOWN LAW | 600 NEW JERSEY AVENUE NW | WASHINGTON, DC 20001 www.oneillinstitute.org 
test. $^{68}$ Thus, for example, EEOC regulations permit the provision of lesser benefits to Medicareage employees, ${ }^{69}$ essentially moving away from a notion of social solidarity and decisively toward actuarial fairness.

Disability. The Americans with Disabilities Act (ADA) applies to employment, ${ }^{70}$ public programs, $^{71}$ and public accommodations, ${ }^{72}$ while Section 504 of the Rehabilitation Act of 1973 prohibits discrimination in federally assisted programs. ${ }^{73}$ At the same time, civil rights laws prohibiting discrimination based on disability provide only limited protections. Both Section 504 and the ADA utilize a restrictive test for measuring who is protected, extending their reach only to "qualified persons with a disability"74 (a group known as "qualified handicapped persons" under Section 504). ${ }^{75}$ The concept of "qualified" is a narrow one, requiring the existence of a physical or mental impairment that restricts major life activities. ${ }^{76}$ Poor health status alone is not enough to trigger disability protections. Furthermore, even if individuals satisfy the "qualified" test, they lose ADA employment protections under ADA Title I once they are no longer considered employed for purposes of ADA protection, even if they remain entitled to "COBRA continuation" health benefits under their ERISA health plans. ${ }^{77}$ Thus, ERISA itself would have to reclassify individuals as "employees" for purposes of continuation coverage for ADA principles to apply.

Title II of the ADA and Section 504 reach public and federally assisted programs, respectively. However, these protections, as with the ADA's public accommodation protections, are limited to access to coverage as well as to methods of administration that result in segregated and isolated treatment of persons with disabilities. ${ }^{78}$ (An interesting question is whether insurers in the individual market could absolutely bar enrollment based on health status, as many now do; ${ }^{79}$ presumably the insurance "safe harbor" provisions of the ADA would permit such complete exclusionary practices if based on actuarially sound principles). ${ }^{80}$ Indeed, the United States Supreme Court explicitly has interpreted Section 504 - the predecessor law to the ADA - as permitting state Medicaid agencies to apply across-the-board coverage limitations on all recipients, regardless of whether the impact of such limitations is felt disproportionately by qualified persons with handicaps as a result of their greater health needs. ${ }^{81}$

Similarly, the public accommodations provisions of the ADA have been held not to reach the content of insurance. Thus, private health insurers can single out certain conditions (e.g., HIV/AIDS) for complete or near-total coverage exclusion, so long as the exclusion applies to all plan members. This very limited approach to what it means not to discriminate against qualified individuals has been upheld in a health insurance context even in cases in which, by its own admission, the insurer can offer no actuarial data to justify diagnosis based-discrimination. ${ }^{82}$ Thus, despite rulings by the federal agencies to the contrary, courts have deferred to the concepts of actuarial fairness and risk classification, even where actuarial justification is absent, in apparent violation of the ADA's insurance safe harbor, which permits differentiation only when actuarially justified. ${ }^{83}$

In sum, the ADA (and where applicable, Section 504) may prevent employer-sponsored health plans, public insurers, and state regulated private insurers from refusing to sell products to or barring enrollment of qualified persons with disabilities. And both laws would appear to bar administration practices that result in isolation and segregation. But neither law prohibits content design (i.e. what is covered) that differentially affects persons with disabilities, nor does either law affect differential premiums.

O’NEILL INSTITUTE FOR NATIONAL AND GLOBAL HEALTH LAW GEORGETOWN LAW | 600 NEW JERSEY AVENUE NW | WASHINGTON, DC 20001 www.oneillinstitute.org 


\section{B. The Health Insurance Portability and Accountability Act (HIPAA)}

HIPAA establishes certain minimum standards for the design and operation of ERISA-governed health benefit plans, as well as state-regulated health insurance products in both the group and individual markets. Its provisions establish certain limited protections as well as certain types of bars against discrimination based on health status. Because its provisions focus on health status rather than disability, HIPAA has a potentially broader reach than the ADA. At the same time, HIPAA, like the ADA and Section 504, does not reach the content of coverage, nor does it affect the ability of insurers selling in the individual market to charge differential premiums based on health status. Thus, as with the ADA and Section 504, HIPAA's protections apply only at the point of entry into coverage, not to the terms of coverage themselves. HIPAA mandates only that provision be made to allow enrollment by certain people in poorer health status and that ERISA plans and group plans ensure identical treatment of persons in poorer health with respect to enrollment, coverage, and premiums.

HIPAA amends ERISA, the Public Health Service (PHS) Act, and the Tax Code to reach ERISA-governed group health plans, whether self-insured or fully insured, as well as stateregulated insurance products in the group market (and with respect to certain provisions, the individual market). ${ }^{84}$ In effect, HIPAA sets a federal floor on state regulation of the small group market, with very limited provisions applicable to the individual market. ${ }^{85}$

Guaranteed Issue and Renewability in the State-regulated Small Group and Individual Markets. HIPAA defines a small group as one that has at least two but no more than 50 employees on any business day during the preceding calendar year and that employs at least two persons on the first day of the plan year. ${ }^{86}$ At the same time, the small group definitions apply only to the extent that a state has not enacted an "alternative mechanism," thereby permitting states to essentially devise their own methods for complying with HIPAA's small group standards. ${ }^{87}$ The small group standards have as their centerpiece guaranteed issue, meaning that insurers operating in the market must accept every group that applies for coverage, as well as every individual within each group. ${ }^{88}$ Even so, insurers may impose minimum contribution and participation requirements as long as they do not selectively offer their approved products to different employer groups. ${ }^{89}$

Guaranteed issue requirements also apply in the individual market, but in a particularly limited way; the protections apply only to applicants who have not experienced more than a 63-day break in coverage, have exhausted COBRA or other continuation coverage, previously had at least 18 months of creditable coverage, ${ }^{90}$ are ineligible for any other coverage, and have not committed fraud or been terminated for nonpayment of premiums. ${ }^{91}$ Thus, only a fraction of all persons who might need guaranteed issue in the individual market would qualify for such a protection under the terms of the statute.

The guaranteed issue provisions are accompanied by guaranteed renewal requirements, but as with guaranteed issue, the guarantees come with constraints, including the right of insurers to terminate based on "noncompliance with material plan provisions" away from the area covered by a plan's provider network in the case of networked plans. ${ }^{93}$ In other words, the issuer would not have to adjust its network to assure access in the event that group members move. The Centers for Medicare \& Medicaid Services (CMS), the federal

O’NEILL INSTITUTE FOR NATIONAL AND GLOBAL HEALTH LAW GEORGETOWN LAW | 600 NEW JERSEY AVENUE NW | WASHINGTON, DC 20001 www.oneillinstitute.org 
agency that administers HIPAA under the PHS Act, interprets discontinuances, terminations, and non-renewal to cover rescissions. ${ }^{94}$ Similar renewal rules apply in the individual insurance market. $^{95}$

HIPAA's reach is further limited by its terms of enforcement; the law gives states several basic compliance options, with limited to no federal oversight of the operation of whether state alternatives satisfy HIPAA's requirements. Under HIPAA, states can adopt and enforce federal requirements; alternatively they can have the federal government enforce HIPAA requirements for them. ${ }^{96}$ Yet another alternative - elected by 48 states as of Fall 2007 - is to establish "alternative mechanisms" for achieving compliance. ${ }^{97}$ There appears to be a vacuum of federal oversight regarding the extent to which states' alternative models satisfy HIPAA, ${ }^{98}$ despite the fact that the alternative mechanisms must be cleared by CMS in order to ensure that all "federally eligible" ${ }^{99}$ individuals enjoy guaranteed issue protections.

States that elect to establish an alternative mechanism in the individual market can offer a high risk pool (much like a bad driver pool in the case of auto insurance). News accounts suggest that the cost of high risk pools appears to be so prohibitive as to be virtually financially inaccessible. $^{100}$ Furthermore, recent litigation involving insurer rescissions in the individual market underscore the limited nature of federal oversight of HIPAA's guaranteed issue requirement. $^{101}$

Prohibiting Pre-Existing Condition Exclusions. In order to address issues of portability (that is, being able to change jobs without fear of a wholesale or partial exclusion from a subsequent plan), HIPAA provides certain prohibitions against pre-existing condition exclusions. As with guaranteed issue, however, the term is defined narrowly under federal law as "a condition, either physical or mental, for which medical advice was recommended or received within a six-month period ending on the enrollment date.”102 This definition thus can exclude longstanding conditions that were not recently treated (e.g., cancer that was successfully treated and that has been in remission for years). Furthermore, the prohibition applies only to persons who have "creditable coverage" and who obtain new coverage within 63 days of losing "creditable coverage." ${ }^{103}$ Rules for calculating when creditable coverage exists and its duration are extensive. ${ }^{104}$ Furthermore, HIPAA offers no protection for newly eligible plan members without previous creditable coverage. Health benefit plans and insurers can impose up to a 12-month pre-existing condition exclusion (which may be longer under certain circumstances), ${ }^{105}$ except in the case of pregnancy, the addition of a newborn child, or a newly adopted child within 30 days of adoption. 106

Access to Coverage: Prohibition against Health Status Discrimination. HIPAA's central purpose was to eliminate health status considerations from eligibility for coverage or from the cost of coverage in the group market. HIPAA thus prohibits certain types of discriminatory actions by ERISA-governed plans and state regulated issuers of group health insurance (the nondiscrimination provisions do not apply to the individual market). ${ }^{107}$ The range of prohibited conduct spans enrollment, effective date of coverage, waiting periods, late and special enrollment rules, eligibility for benefit packages, benefits (both cost sharing and benefit restrictions), continued eligibility, and coverage termination. ${ }^{108}$ Specific prohibited bases of discrimination include health status, medical health condition (mental or physical), claims experience, the receipt of care, medical history, genetic information, evidence of insurability, and disability. ${ }^{109}$

O’NEILl INSTITUTE FOR NATIONAL AND GLOBAL HEALTH LAW GEORGETOWN LAW | 600 NEW JERSEY AVENUE NW | WASHINGTON, DC 20001 www.oneillinstitute.org 
Thus, HIPAA prohibits differential treatment in enrollment or coverage in the case of ERISA health benefit plans and products sold in the state regulated group health insurance market. At the same time, HIPAA does not reach content (i.e. what is covered) nor premium cost, so as enrollment barriers are removed for members of groups or benefit plans, premiums can rise and coverage can shrink. Hence the paradox of non-discrimination prohibition that are unaccompanied by minimum content and cost-sharing requirements as well as limits on the amount of financial liability for premiums facing individuals and families.

Although HIPAA bars discrimination, the law does not prohibit an employer or insurer from offering premium discounts or modified cost sharing in exchange for participation in a bona fide wellness program. ${ }^{110}$ In other words, HIPAA allows rewards for participation in health promotion programs that are part of a group health plan as long as the reward is not tied to a particular health factor and is available to all similarly situated employees. Thus, a plan could reward employees who undergo a risk assessment upon enrollment (or penalize those who do not), but cannot reward only plan participants whose participation results in lowered cholesterol levels. Federal regulations also permit "benign discrimination," 111 that is, provision of a reward targeted to individuals with certain conditions, such as rewarding persons with diabetes for participating in a disease management program, as long as the reward is not conditioned on the achievement of a certain outcome. ${ }^{112}$

Whether wellness policies ultimately serve to discriminate against persons in poor health by penalizing them for their failure to aggressively take charge of their health remains to be seen. ${ }^{113}$ Paradoxically of course, the widespread use of wellness programs in an era of shrinking coverage ultimately may help illustrate the shortcomings of the current approach to nondiscrimination. Suppose that a self treatment plan for diabetes recommends frequent and comprehensive podiatric care, an important and effective treatment for persons with serious diabetes that can avert the loss of limbs. Then imagine that the plan limits or excludes podiatric care. Could a plan member be penalized for failing to follow a self-care protocol while simultaneously being denied coverage for the evidence-based treatment in question?

\section{The Genetic Information Non-Discrimination Act (GINA)}

The Genetic Information Non-Discrimination Act (GINA) amplifies HIPAA's nondiscrimination rules by prohibiting employee health benefit plans and state regulated insurers from using genetic information to determine eligibility for coverage, a prohibition extended to both the group and individual markets. ${ }^{114}$ GINA goes beyond HIPAA, however, in prohibiting the use of such information to determine the level of premiums to be charged in the case of both ERISA governed health plans and the state regulated group and individual markets. ${ }^{115}$ Both individual medical underwriting of applicants and the purchase of aggregate data are prohibited. ${ }^{116}$ In this sense, GINA can be seen as a further incremental movement toward the concept of social solidarity in its prohibition against risk classification based on a dormant, but immutable health status marker. At the same time, GINA does not bar medical underwriting based on current health status, nor does it affect the content of coverage. ${ }^{117}$

O’NEILl INSTITUTE FOR NATIONAL AND GLOBAL HEALTH LAW 


\section{Mental Health Parity}

The Paul Wellstone and Pete Domenici Mental Health Parity and Addiction Equity Act, included in the Wall Street rescue plan passed by Congress in 2008, ${ }^{118}$ addresses the issue of coverage discrimination based on health status to a limited degree, even as it preserves the power of health plans and insurers to either entirely exclude coverage of mental illness conditions or impose stringent medical management limits on coverage in ways far different from techniques used in the design and administration of physical health conditions and treatments. Amending ERISA, the Tax Code, and the PHS Act, mental health parity extends the concept of parity (which previously barred only the use of lifetime and annual financial caps on mental health benefits) to reach "predominant"119 "financial requirements" and "treatment limitations" more generally. In other words, the Act ensures that financial requirements and treatment limitations applicable to mental health/substance use disorder benefits are no more restrictive than those requirements and limitations placed on medical/surgical benefits. The term "financial requirement" is expanded to include deductibles, copayments, and coinsurance; ${ }^{120}$ the term "treatment limitation" includes "limits on the frequency of treatment, number of visits, days of coverage, or other similar limits on the scope or duration of treatment." ${ }^{121}$ In addition, the legislation establishes at least some level expectation of parity in access to out-of-network providers, requiring a level of parity "that is consistent with the requirements of this section." ${ }^{122}$

At the same time, while the legislation requires disclosure of medical necessity criteria, ${ }^{123}$ it does not compel parity in definitions and terms, such as those that define the medical necessity of care, unless such terms fall within the revised meaning of parity. ${ }^{124}$ As a result, the legislation does not appear to prohibit coverage techniques that embed practice guidelines into coverage, such as "acute short term hospitalization for addiction," and that avoid express numerical limits. Thus, parity does not appear to prevent a more granular approach to mental illness and addiction coverage, one that embeds precise, permissible treatments into coverage documents, even while using more broad-based coverage terms for other conditions.

How the parity amendments are interpreted of course remains to be seen, but the embedding of pre-set practice guidelines into the terms of coverage is vastly different in structure and consequence from traditional insurance design practices. In ERISA coverage cases involving physical health care, ${ }^{125}$ the contract specifies broad covered benefit classes, with delegation of decision-making discretion to the insurer or plan administrator to decide whether particular treatments are covered (i.e., fall within the enumerated classes) and medically necessary for a particular patient. In these cases, the subject of an appeal is the extent to which the insurer may have abused its discretion in applying broad coverage terms to a particular case. ${ }^{126}$ By contrast, coverage documents that employ embedded treatment guidelines fix the treatment as a contract term, thereby eliminating the right to appeal, since challenges to plan design itself are impermissible under ERISA. ${ }^{127}$

The implications for mental illness and addiction treatment are revealed in an important case ${ }^{128}$ that involved a beneficiary challenge to plan coverage limitations that, in her view, restricted treatment for her addiction to levels too low to achieve results. She appealed for additional coverage in the form of a longer treatment program. The treatment that had been authorized by the plan was expressed, not as an administrator's discretionary decision applying broad benefit classes, but instead as a specified "condition/treatment" pair that was enumerated within the terms of the contract itself. That is, the contract specified treatments much in the way that a

O’NEILl INSTITUTE FOR NATIONAL AND GLOBAL HEALTH LAW

GEORGETOWN LAW | 600 NEW JERSEY AVENUE NW | WASHINGTON, DC 20001 www.oneillinstitute.org 
plan's prescription drug component specifies coverage in the form of a prescribed drug formulary. As a result, the plan administrator essentially was stripped of its discretion to cover more services even if necessary and the claimant had no appeals rights because the limitations were fixed by contract rather than discretionary. In effect, the contractual specification of treatment essentially nullified the need for an individualized medical necessity determination, since coverage consisted of defined treatments rather than a plan design requiring individualized, fact-driven decision-making.

By not incorporating parity in medical necessity into its provisions, the 2008 parity legislation does not appear to change plan discretion to use a more granular fixed concept of medical necessity that utilizes a fixed approach to identifying and covering medically necessary mental health treatment. Thus, not only does the legislation allow plans and insurers to entirely exclude conditions from coverage, but furthermore, the law appears to permit insurers to designate covered medically necessary treatments contractually and without according plan administrators the discretion to make individualized coverage determinations within broader benefit classes. The physical health analogy to this approach to coverage would be exclusion of certain cancers from coverage entirely and the specification of covered cancer treatments without giving the plan administrator the discretion to recognize individual variation and tailor coverage accordingly.

It may be that the approach taken to mental health coverage signals the general direction of coverage in an evolving health care system in which financing is more closely aligned with evidence-based treatments. For the time being, the parity legislation tolerates differences in approach to coverage design (i.e., what is covered) and plan administration in a medical necessity context.

\section{E. Newborns and Mothers Protection Act}

As with other acts within this collection of laws, the Newborns and Mothers Protection Act amends the Tax Code, ERISA, and the PHS Act, reaching both the state regulated group market and employer plans subject to the Pregnancy Discrimination Act (15 employees or more). ${ }^{129}$ Covered plans and issuers must provide a minimum of 48 hours stay following a normal delivery, and 96 hours following a C-section ${ }^{130}$ (an earlier discharge may occur if recommended by the health care provider). The Act also addresses other dimensions of parity, such as prohibiting plans from denying enrollment, renewal or continued coverage to mothers or newborns covered by the Act or penalize providers that comply with the Act or incentivize them to shorten the length of stay. ${ }^{131}$

\section{F. Women's Health and Cancer Rights Act (WHCRA)}

Amending ERISA, the Tax Code, and the PHS Act, WHCRA applies to group health plans that provide mastectomy benefits, requiring plans to cover breast reconstruction, prostheses, and other treatments to address the complications of all stages of a mastectomy. ${ }^{132}$ As with the

Newborns and Mothers Protection Act, WHCRA prohibits retaliation against providers or the exclusion of persons protected by the Act.

O’NEILl INSTITUTE FOR NATIONAL AND GLOBAL HEALTH LAW

GEORGETOWN LAW | 600 NEW JERSEY AVENUE NW | WASHINGTON, DC 20001 www.oneillinstitute.org 


\section{G. ERISA Regulations Governing Full and Fair Review of Claims Denials}

As this section describes, ERISA has been revised on several occasions to address certain types of health plan conduct in connection with enrollment and coverage. COBRA continuation benefits are one example and the amendments noted above offer other examples. In addition, regulations promulgated in 2000 in order to revise the "full and fair hearing" provisions of ERISA by establishing more speed and transparency to reviews of health coverage denials, may have some effect on improved access to benefits by persons in poor health status. At the same time, the rate at which appeals take place appears to be very low, and as a result, the impact of changes in the fair process laws may be limited. ${ }^{133}$

\section{Proposed Legal Solutions}

This analysis reviews the problem of discrimination on the basis of health status, as well as the series of laws that have attempted to address the problem. The focus of this analysis is on federal law; many states have enacted similar laws that parallel these federal themes. ${ }^{134}$ Taken together, the federal legal environment indicates a growing interest in mitigating discrimination, particularly at the point of enrollment into coverage. But this review also underscores the limited nature of these protections and the degree to which federal policy has yet to focus on reforms that affect the design and content of coverage itself. Indeed, by zeroing in on lifting "entrypoint" discrimination, the laws may have inadvertently triggered efforts by health plans and insurers to move toward the use of greater risk shielding techniques in relation to coverage itself, including higher cost sharing, thinner benefits, a specified contractual approach to coverage decisions that removes the discretion to allow treatment as a matter of individualized medical judgment (especially in the case of certain conditions considered risky), and the greater use of "macro-level" treatment exclusions. Put another way, reducing discrimination against the sick at the front end may have resulted in greater discrimination against those who do manage to enroll, thereby triggering a rapid escalation in the proportion of under-insured persons.

Federal laws outlining minimum coverage requirements, such as those aimed at improving coverage for certain conditions (pregnancy, newborn inpatient stays, breast cancer), nibble around the edges of coverage design. Furthermore, laws aimed at ensuring guaranteed entry into coverage arrangements contain numerous limitations and loopholes, such as non-discrimination on the basis of pre-existing conditions that restricts its reach to persons who have not recently been in treatment (within 6 months), or who have continuous and unbroken coverage (an impossible bar for persons who have lost employment because of illness, given the attendant effects of job loss on income). Indeed, COBRA, which ostensibly permits former employees who are sick to remain members of their plans, carries an unsubsidized premium that makes it all but unattainable to the very people in need of continuation coverage. Disability law is of limited utility, because the definition of who is a qualified person with a disability is narrow. Furthermore, the ADA and Section 504 have been interpreted as not reaching the content of coverage; even if this limiting interpretation were to be reversed, the ADA's "insurance safe harbor provision" (as well as courts' willingness to waive the need for even a remotely colorable actuarial justification of a claim of elevated financial risk) ${ }^{135}$ means that even qualified persons with disabilities gain no protection from the law.

O’NEILl INSTITUTE FOR NATIONAL AND GLOBAL HEALTH LAW 
Devising a solution to this problem in a health care system that largely rests on market principles of actuarial fairness is not simple, since the heart of actuarial fairness is distinction based on health status. However, certain reforms, outlined below, could be expected to have important mitigating effects.

\section{A. The Legal Establishment of a Nationwide Group Purchasing Mechanism}

Currently few legal mechanisms exist for creating groups in the marketplace outside of employment; furthermore, most employee groups are too small to be sufficiently robust in relation to the financial risk of illness. As a result, the illness of a few typically leads to escalating premiums unless the sick are pushed out (a seemingly endless process until no one is left in the group). Small and mid-sized employers, like individuals, are essentially micro-groups. Even large and jumbo employers are, in the vast scheme of things, limited pooling arrangements where health risks are concerned, given an aging population and the relatively poor health profile of far too many Americans.

Thus, the most basic step in crafting a legal solution to discrimination is enactment of new federal legislation to establish a nationwide purchasing group, much in the way Massachusetts' health reform plan establishes a state-level group. The argument for a national group - like that which undergirds the Federal Employee Health Benefits Plan or the Medicare Part D prescription drug program - is its sheer size and ability to sustain financial risk. State pools, such as the one in Massachusetts, might be feasible for large states with relatively healthy populations, but less so for smaller states with older populations or populations in relatively poor health. Legislation to establish a nationwide purchasing group (which of course could be subdivided into state or regional purchasing markets) resolves this distributional issue while also preventing insurers from selecting state-based markets with healthier populations and thus, lower risk.

As the insurance industry already points out in its own health reform recommendations, ${ }^{136}$ compulsory enrollment is a crucial precondition to the ability to eliminate barriers to enrollment tied to health status in order to prevent adverse selection. Presumably therefore, legislation to establish the pool would also provide for guaranteed issue and renewal, a total bar against preexisting condition exclusions, and bars against discrimination in access to coverage based on health status. Unlike existing HIPAA standards as noted above, the legislative standards established for a nationwide group could be defined to eliminate the restrictions and limitations that dilute HIPAA's current effectiveness (e.g., the ability to exclude certain pre-existing conditions from coverage).

In a fully realized version of this legislative approach, all Americans could be automatically enrolled in a national purchasing pool, with opt-out provisions for those covered through employer-sponsored plans or other remaining forms of "creditable coverage." ${ }^{137}$ Enrollment into the pool could be supported through income-related subsidies (a combination of taxes and direct payments) that would cover the cost of enrollment, with collection of premiums a function of the federal tax system coupled with alternative payment mechanisms for individuals who do not pay taxes.

In the case of employers who desire to retain their own coverage arrangements, the national purchasing pool could serve as a reinsurance mechanism in order to protect employer groups against high losses for covered benefits. This use of the federal pooling mechanism would permit

O’NEILl INSTITUTE FOR NATIONAL AND GLOBAL HEALTH LAW

GEORGETOWN LAW | 600 NEW JERSEY AVENUE NW | WASHINGTON, DC 20001 www.oneillinstitute.org 
employers (whether ERISA governed or exempt as in the case of public employers) to utilize the pool as a reinsurance mechanism, with a legislatively established "attachment point" (i.e., the point at which reinsurance coverage begins). ${ }^{138}$

In the case of individuals whose coverage is derived directly from the pool, the legislation also could provide for payment of risk-adjusted premiums to participating plans, thereby utilizing actuarial experience not as a means of excluding or limiting coverage, but as a mechanism for recognizing the realities of different health status at the point of distribution among participating plans.

A further consequence of a national pool would be elimination of the need for an individual market. If a nationwide purchasing pool is made available to all persons as a matter of law, then there is no need for an individual market, which by definition exists to discriminate, since all persons seeking coverage through the individual market are effectively a high risk.

\section{B. Minimum Participation Standards for Sellers of Health Benefit Services Products; Non- Discrimination Against the Sick in Coverage Design and Coverage Determinations; Non- Discrimination in Provider Payment and Network Formation}

Whether selling to individuals insured through the pool or through an employer reinsured through the pool, entities that seek to sell health benefit products could be required to meet coverage standards. Those standards presumably would include a benefit design pegged to the Federal Employee Health Benefit Plan or another widely purchased "benchmark" plan, an approach similar to that used in the case of the State Children's Health Insurance Program. ${ }^{139}$ At the same time, the current minimum coverage standards applicable to ERISA plans (e.g., pregnancy non-discrimination, coverage of mothers and newborns, coverage of women with breast cancer, and mental health parity) could be applied to all products sold through the pool, whether directly or to employers reinsured through the pool, with cost sharing similarly regulated.

A far more complex question relates to how to address the phenomenon discussed previously: coverage design approaches that discriminate through exclusion of recognized medical conditions and the use of contractual treatment strategies for other conditions in order to avoid insurer discretion to authorize more expansive or alternative coverage. This bifurcated approach to coverage design - broad classes and medical discretion for some conditions, total exclusion of other conditions, and non-discretionary contractual treatments for still others - is inherently discriminatory based on health status.

One plausible answer is that, in fact, coverage generally is moving toward the designation of conditions and treatments and the elimination of medical discretion, particularly as evidence builds regarding the effectiveness of treatment. If this is the case - that is, if coverage design for both physical and mental conditions increasingly resembles a specified formulary - then the most logical response would be the enactment of standards that permit this evolution to occur while simultaneously enacting laws barring the exclusion of any recognized medical condition and creating an exceptions process for recognized conditions for which the recognized treatment is inappropriate. While contractual condition/treatment pairings may ultimately serve population-wide interests, a small but significant proportion of the population have complex conditions that simply do not fit neatly into recognized condition/treatment pairs. Without a

O’NEILl INSTitute FOR NATIONAL AND GLOBAL HEALTH LAW

GEORGETOWN LAW | 600 NEW JERSEY AVENUE NW | WASHINGTON, DC 20001 www.oneillinstitute.org 
legal remedy, these individuals and their treating professionals face the difficult choice of either accepting coverage for inappropriate treatment or alternatively, going without coverage at all.

In order to guard against such an outcome, one legal option is to include in the legislated coverage standards an "exception" system similar to the exceptions process that is an element of the Medicare Part D prescription drug benefit program. ${ }^{140}$ This process allows coverage exceptions to gain access to medically necessary prescription drugs not covered under Part D plans' formulary for individuals whose need for appropriate treatment is not satisfied through the standard formulary design. A national coverage arrangement could provide a similar exceptions process, permitting coverage for "extra contractual" treatments based on specified evidence such as the clinical judgment of treating professionals, evidence gleaned from the health services research literature and studies, and expert opinion. In reviewing a request for an exception, presumably a discretionary review standard paralleling the current ERISA fiduciary standard would apply; ${ }^{141}$ to further militate against arbitrary denials, the internal review process could be coupled with an independent external appeals system permitting an impartial de novo external review, followed by limited judicial review based on the record. This approach has been utilized by Congress previously in so called "patients' bill of rights" legislation, ${ }^{142}$ which has not been considered since 2001, but whose provisions are highly relevant to any effort to develop procedural mechanisms governing claims determinations.

A further measure of reform would be to require the development of risk-adjusted payment methodologies, not just to plans selected by enrollees, but also with respect to provider payments, in order to incentivize higher or more intensive levels of care for patients whose underlying conditions require a more complex level of care. For example, filling a cavity for a healthy 10-year-old with no other health conditions other than cavities may bear little or no practical relationship to filling a cavity for a 10 -year-old who also has serious autism. Dental treatment is necessary for both children, but the resemblance in terms of time and resources may end there. In addition, legal safeguards would be required to ensure that providers with experience in the treatment of patients with complex conditions are not arbitrarily excluded from coverage networks as an indirect means of shielding plans against higher risk patients.

\section{Medicaid Reforms}

As noted, Medicaid plays a vital role in a market based system that differentiates among individuals based on health status with respect to both coverage and care. The question is whether Medicaid remains equally essential in a world in which all persons are enrolled in a common purchasing arrangement. One approach would be to retain Medicaid for those individuals who meet its conditions, that is, to segregate these individuals from the broader pool. The benefit of this approach is protection of the larger pool from higher health risks. The downside is, of course, the impact of such segregation on Medicaid beneficiaries. While coverage is broad and cost-sharing is highly controlled, Medicaid provider participation levels are extremely low, chiefly because of very low payment rates. ${ }^{143}$ Whether to continue to segregate low income persons in a separate risk pool thus becomes a pressing matter in a health care quality context.

Certainly Congress could amend the Medicaid statute to create far more explicit standards than those that currently apply in order to ensure that payment levels are sufficient to ensure equality of health care access. ${ }^{144}$ Another legal option however, would be to retain Medicaid as a source

O’NEILl INSTITUTE FOR NATIONAL AND GLOBAL HEALTH LAW

GEORGETOWN LAW | 600 NEW JERSEY AVENUE NW | WASHINGTON, DC 20001 www.oneillinstitute.org 
of coverage for what commonly is termed "long-term care," that is, community and institutional services and supplies that are essential to maintaining health and averting deterioration among children and adults with highly advanced health care needs. Even in a broad pooling arrangement such as the one proposed here, with uniform and regulated coverage standards and safeguards against discrimination, it is likely that the coverage design will not encompass those classes of services that extend beyond services connected with comprehensive primary care, such as treatment for acute physical and mental conditions, and the routine management of certain types of chronic health conditions such as diabetes, cardiovascular disease, asthma, mild to moderate depression, and other conditions amenable to modern "disease management" techniques. ${ }^{145}$

However, a small portion of the population experiences conditions of sufficient duration and severity to require more intensive types of health care and supportive services on an ongoing basis, examples of which include nursing facility services, personal care services, specialized forms of durable medical equipment, private duty nursing care, habilitation services, long term rehabilitation, specialized case management, and other forms of care that extend beyond the furthest reaches of even a generous insurance policy. Medicaid's strength is its coverage of service classes that have no counterpart in traditional health insurance, ${ }^{146}$ and over four decades, the program has become the nation's predominant source of health care financing for these services. Even if Congress were to enact a national purchasing pool with strong nondiscrimination standards with respect to both enrollment and coverage of the type visualized here, it is likely that the pool would exclude items and services at the long-term care end of the health care spectrum, much as Medicare does not cover long-term care.

In order to ensure that persons with advanced health care needs are covered for long-term care, Medicaid could be amended to provide long-term care coverage for persons who receive standard coverage through the pool (either directly or as a function of participation in a reinsured employer-sponsored plan). Eligibility could be conditioned on a need for long-term care services as a result of a specified level of functional limitation, a model that has been used previously by Congress to establish Medicaid coverage for persons in need of long-term care. ${ }^{147}$ This tiered approach to coverage could finance items and services needed by children and adults with special health care needs, such as school-based intensive health care services for children receiving early intervention or special education, specialized care for children receiving services through the child welfare system, children and adults with severe mental and emotional disorders, and persons who experience significant limitations of daily activities and who require specialized care in community or institutional settings.

As with previous Medicaid initiatives targeted at assisting persons with significant disabilities, enrollment could be income-related. ${ }^{148}$ As with the current Medicaid program, the model of administration could remain one of state administration subject to federal requirements regarding eligibility, enrollment, coverage, quality oversight, and plan administration. In essence, under this proposal, Medicaid would evolve into a funder of long-term care services for the population, with a nationwide purchasing pool for the non-elderly population employed to furnish a more standard range of health care needs.

O’NEILL INSTITUTE FOR NATIONAL AND GLOBAL HEALTH LAW 


\section{Concluding Thoughts: Short Term Reforms}

The solutions laid out here take a long term view of the problem of discrimination, with an eye toward the system evolution envisioned in President Obama's campaign health reform proposals. That system depends on the establishment of a national health insurance exchange for purposes of guaranteeing accessible and affordable coverage. This analysis lends additional justification for such an approach, since moving in the direction of a nationwide coverage arrangement also mitigates discriminatory enrollment and coverage practices. In such a reformed system, Medicaid also could be reconfigured to focus on the population's long-term health care needs.

Of course, achieving this type of evolution is viewed as a lengthy process. What interim steps might be taken to provide more immediate legal relief?

- Congress might amend HIPAA to strengthen its protections against exclusion based on pre-existing condition, by repealing the current treatment exception.

- Congress also could strengthen its guaranteed issue provisions to eliminate the continuous coverage requirement.

- Congress also might incentivize states to establish Massachusetts-like group markets by enacting stop-loss protections in states that elect to establish state-based risk pools, which in turn would also obviate the need for the individual insurance market. Federal stop-loss could contain protections against discrimination and exclusion in enrollment, with states given more latitude to design coverage.

- Congress might also enact legislation to finance COBRA, thereby enabling more individuals with serious health conditions to retain their attachment to an employer group, not only as a means of deriving coverage but in order to protect guaranteed issue rights.

- In addition to extending coverage to low income adults, Congress might create a new state Medicaid eligibility option to extend Medicaid coverage to any child or adult who has been rejected from the individual insurance market or whose premiums exceed $5 \%$ of gross family income on an annualized basis. This option might be in addition to or in lieu of state risk pool legislation, and would use Medicaid to achieve coverage of individuals with pre-existing conditions who are not connected to a group, and thus who require entry into the individual market. The benefit of this approach is readily available federal financial participation (which could be enhanced), strong coverage, and controlled costsharing. The shortcoming, as noted previously, is the health care access barriers faced by recipients. Nonetheless, Medicaid has been demonstrated to have a powerful impact on access to health care, and as an interim step holds much promise as an alternative to the current individual market.

Finally, there are steps that could be taken administratively to reduce insurance discrimination based on health status. In implementing mental health parity, the United States Departments of Health and Human Services, Treasury, and Labor could impose limits on the extent to which insurers and plans can utilize treatment limits that differentiate between covered physical and mental health conditions in terms of the extent to which additional coverage can be authorized when medically necessary. While the 2008 amendments do in fact permit discrimination in the form of condition exclusions, the question of whether plans and insurers can use fixed treatments for mental conditions while more flexible approaches for physical conditions remains an open one.

O’NEILL INSTITUTE FOR NATIONAL AND GLOBAL HEALTH LAW

GEORGETOWN LAW | 600 NEW JERSEY AVENUE NW | WASHINGTON, DC 20001 www.oneillinstitute.org 
Furthermore, the federal government could be far more robust in overseeing state compliance with HIPAA's non-discrimination and guaranteed issue requirements in the state regulated health insurance markets. The evidence suggests that state high-risk pools are inaccessible, thereby calling into question states' reliance on such pools in lieu of implementation of HIPAA's protective standards. This suggests the need for conditions for high risk pools, in order to guarantee that such pools do not become a subterfuge for HIPAA non-compliance.

What appears a far less viable remedy - either in the short term or long term - is a solution that relies on the use of high risk pools. In concept, such pools have some attraction, because they arguably offer a means of achieving coverage for persons unable to secure insurance through "mainstream" plans. Risk pools, however, have the potential to isolate the sick into costly and separate coverage arrangements; furthermore, they can incentivize markets to be more discriminatory in both access and coverage, on the theory that a high risk pool will be there to catch those who are excluded. In the end, high risk pooling appears to be an approach whose effect is to exclude the sick and those who fall outside an artificially defined health norm. With the potential for an ever-shifting concept of what a healthy norm is, a high risk pool cannot address the reality of how people's health can change. An individual in good health today can become the person with cancer tomorrow. In order to provide an effective means of financing appropriate health care, which is the whole point of the enterprise after all, health insurance must recognize the oftentimes fleeting nature of good health, and must provide for stable coverage arrangements that can assure access to appropriate care both in good health and bad.

O’NEILL INSTITUTE FOR NATIONAL AND GLOBAL HEALTH LAW 
${ }^{a}$ J.D. Harold and Jane Hirsh Professor of Health Law and Policy, Chair, Department of Health Policy, The George Washington University School of Public Health and Health Services

${ }^{1}$ Cathy Schoen, et. al., "How Many are Underinsured? Trends Among U.S. Adults, 2003 and 2007," The

Commonwealth Fund, June 10, 2008, available at

http://www.commonwealthfund.org/publications/publications_show.htm?doc_id=688615 (last visited November 30, 2008).

${ }^{2}$ D. Himmelstein, et al., "Illness and Injury as Contributors to Bankruptcy,” Health Affairs Web Exclusive," W563-73 (2005), available at

http://content.healthaffairs.org/cgi/reprint/hlthaff.w5.63v1?maxtoshow=\&HITS=10\&hits=10\&RESULTFORMAT= \&author1=Elizabeth+Warren\&andorexactfulltext=and\&searchid=1\&FIRSTINDEX=0\&resourcetype=HWCIT (last visited November 30, 2008).

${ }^{3}$ J.Z. Ayanian et al., "Unmet Health Needs of Uninsured Adults in the U.S.,” JAMA, 284, no. 16 (2000): 2061-2069.

The authors report that "adults whose self-reported health status was good, fair, or poor were 2 to 3 times more likely to have been uninsured for 1 year or longer than those who reported excellent or very good health," at 2064.

${ }^{4}$ America's Health Insurance Plans, "Health Plans Propose Guaranteed Coverage for Pre-Existing Conditions and Individual Coverage Mandate,” November 19, 2008, available at http://www.ahip.org/content/pressrelease.aspx?docid=25068 (last visited November 30, 2008) (linking guaranteed coverage without pre-existing condition exclusions to an individual coverage mandate.)

${ }^{5}$ Although, as discussed in this paper, insurance discrimination can in fact constitute a civil rights law violation under certain circumstances.

${ }^{6}$ D. Stone, "Protect the Sick: Health Insurance Reform in One Easy Lesson," Journal of Law, Medicine, and Ethics, 36, no. 4 (2008): 652-659.

${ }^{7}$ Institute of Medicine, Crossing the Quality Chasim, A New Health System for the $21^{\text {st }}$ Century, (Washington, D.C: National Academy Press, 2001): at 25.

${ }^{8} 29$ U.S.C. § 1002(32) (2008).

${ }^{9}$ S. Rosenbaum, “Health Policy Report: Medicaid,” N. Engl. J. Med., 346, no. 8 (2002): 635-640, at 635.

${ }^{10} \mathrm{Id}$.

${ }^{11}$ Perhaps the most vivid example is the state option to cover uninsured women suspected of having breast or cervical cancer. 42 U.S.C. §1396a(a)(10)(A)(ii)(XVIII) (2008) and 42 U.S.C. §1396a(aa) (2008).

1242 U.S.C. §1396a(a)(55) (2008).

${ }^{13}$ Rosenbaum, supra note 9. But states can place reasonable limits on required benefits as long as normative needs are met. See, e.g., Alexander v. Choate, 469 U.S. 287 (1985) (permitting across the board limitations on inpatient hospital coverage even though such limitations reduce coverage below the level needed by persons with disabilities).

${ }^{14}$ K.A. Clifford and R.P. Inculano, "Commentary: AIDS and Insurance: the Rationale for AIDS-related Testing," Harvard Law Review, 100 (1987): 1806-1826, at 1808-1810.

${ }^{15}$ T. Baker and J. Simon, "Embracing Risk,” in T. Baker and J. Simon, eds., Embracing Risk: The Changing Culture of Insurance and Responsibility (Chicago: University of Chicago Press, 2002): at 7.

${ }^{16}$ T.S. Jost, Disentitlement: The Threats Facing our Public Health-Care Programs and a Rights-Based Response (New York: Oxford University Press, 2003): 265-281.

${ }^{17}$ In 2008, 63\% did so. Kaiser Family Foundation, “Employer Health Benefits 2008 Annual Survey,” (2008): at 34, available at http://ehbs.kff.org/pdf/7790.pdf (last visited Nov. 30, 2008).

${ }^{18}$ Id. at 47 . Note $82 \%$ of eligible workers take up coverage when it is offered.

${ }^{19}$ A.B. Monahan, "Health Insurance Risk Pooling and Social Solidarity: A Response to Professor David Hyman," Social Science Research Network, 2008, at 1, available at

http://papers.ssrn.com/sol3/papers.cfm?abstract_id=1124947 (last visited Jan. 26, 2009).

${ }^{20}$ Kaiser Family Foundation, "How Private Insurance Works: A Primer," April 2008, 1-28 at 11, available at http://www.kff.org/insurance/upload/7766.pdf (last visited Nov. 30, 2008) [hereinafter How Private Insurance Works].

${ }^{21}$ Baker and Simon, supra note 15, at 11-12.

${ }^{22}$ How Private Insurance Works, supra note 20, at 5.

${ }^{23}$ Id. at 6 .

${ }^{24}$ M. Crossley, “Discrimination Against the Unhealthy in Health Insurance,” Kansas Law Review, 54 (2005): 73153 , at 85-87.

${ }^{25}$ D. Stone, “How Market Ideology Drives Racial Inequality,” in J. Morone and L. Jacobs, eds., Healthy, Wealthy, and Fair: Health Care and the Good Society (Oxford: Oxford University Press, 2005): 65-89, at 77.

O’NEILl INSTITUTE FOR NATIONAL AND GLOBAL HEALTH LAW

GEORGETOWN LAW | 600 NEW JERSEY AVENUE NW | WASHINGTON, DC 20001

www.oneillinstitute.org 
${ }^{26}$ R. Pear, “Women Buying Health Policies Pay a Penalty,” New York Times, October 29, 2008, at A23.

${ }^{27}$ R. Rosenblatt, et al., Law and the American Health Care System (New York: Foundation Press, 1997): 139-140.

${ }^{28}$ See the wide range of cases discussed in Rosenblatt et al., supra note 28 (2001-2002 supplement). See also

Rosenblatt et al., Law and the American Health Care System (2008 manuscript forthcoming) (available from

Professor Rosenbaum, sarar@gwu.edu).

${ }^{29}$ McEvoy v. Group Health Co-op. of Eau Claire, 570 N.W.2d 397 (Wis. 1997).

${ }^{30}$ McGann v. H. \& H. Music Co., 946 F.2d 401 (5th Cir. 1991); Doe v. Mutual of Omaha, 179 F.3d 557 (7th Cir. 1999).

${ }^{31}$ Bedrick v. Travelers Ins. Co., 93 F.3d 149 (4th Cir. 1996) (reversing in part plan denial of physical and speech therapy for child with cerebral palsy).

${ }^{32}$ Aetna v. Davila, 542 U.S. 200 (2004). See also 42 U.S.C. § 1395w-102 (2008) (permitting Medicare beneficiaries to seek exceptions from prescription drug formulary limitations).

${ }^{33}$ For a description of moral hazard in health insurance see T.S. Jost, Health Care At Risk: A Critique of the Consumer-Driven Health Care Movement (Durham: Duke University Press, 2007): xviii-xx.

${ }^{34}$ For an excellent analysis of the relationship between health and society, see Robert Wood Johnson Foundation to the Commission to Build a Healthier America, Overcoming Obstacles to Health, (February 2008), available at http://www.commissiononhealth.org/PDF/ObstaclesToHealth-Report.pdf.

${ }^{35}$ Rush Prudential HMO, Inc. v. Moran, 536 U.S. 355 (2002) (upholding an Illinois statute requiring HMOs to provide independent review to determine medical necessity of covered services as an insurance regulation that bears directly on the spreading of risk between the insurer and insured).

${ }^{36}$ Kentucky Ass'n of Health Plans, Inc. v. Miller, 538 U.S. 329 (2003) (upholding a Kentucky “any willing provider" law as an insurance regulation affecting the risk pooling arrangement between the insurer and insured).

${ }^{37}$ McEvoy v. Group Health Co-op. of Eau Claire, 570 N.W.2d 397 (Wis. 1997); Krauss v. Oxford Health Plans, Inc., 517 F.3d 614 (2nd Cir. 2008) (upholding plan's decision to withhold full reimbursement for out-of-network care).

${ }^{38}$ For a critique of the consumer driven health care movement and its implications for insurance see Jost, supra note 33, Ch. 3.

${ }^{39}$ Bedrick v. Travelers Ins. Co., 93 F.3d 149, 153 (4th Cir. 1996), (upholding plan’s denial of speech therapy for child with cerebral palsy because plan only covered services to "restore speech").

${ }^{40}$ Doe v. Mutual of Omaha, 179 F.3d 557, 563 (7th Cir. 1999) (upholding differential annual dollar treatment limits for HIV and related conditions).

${ }^{41}$ Jones v. Kodak Medical Assistance Plan, 169 F.3d 1287 (10th Cir. 1999) (upholding health plan's denial of requested long-term alcoholism treatment as a result of embedded and exclusionary treatment guidelines that limited coverage to short term treatment).

${ }^{42}$ Bedrick, 93 F.3d at 154.

${ }^{43}$ Krauss v. Oxford Health Plans, Inc., 517 F.3d 614, 627 (2nd Cir. 2008) (upholding health plan’s denial of full coverage and payment for out of network surgical and aftercare care related to breast cancer).

${ }^{44} I d$.

${ }^{45}$ McGann v. H. \& H. Music Co., 946 F.2d 401, 407-408 (5th Cir. 1991) (upholding HIV/AIDS treatment limits).

${ }^{46}$ Firestone Tire and Rubber Co. v. Bruch, 489 U.S. 101 (1989) (applying lesser standard of review for challenges to plan denial of coverage if the plan gives the administrator or fiduciary discretionary authority to construe the terms of the plan); Metropolitan Life Ins. Co. v. Glenn, 128 S.Ct. 2343 (2008) (holding that courts should employ abuse of discretion standard of review only when there is conflict of interest arising from dual role of an entity as ERISA plan administrator and payer).

${ }^{47}$ S. Rosenbaum et al., "Who Should Determine When Health Care is Medically Necessary?” N. Eng. J. Med., 340, no. 3 (1999): 229-232, at 231.

${ }^{48}$ In this regard, regulations published by the Department of Labor in 2000 limit the discretion of plan administrators to design the appeals process in the case of appeals involving the denial of claims for health benefits. 29 C.F.R. § 2560.503-1(h) (2008).

${ }^{49}$ Metropolitan Life Ins. Co. v. Glenn, 128 S.Ct. 2343, 2347 (2008).

${ }^{50}$ Kentucky Ass'n of Health Plans, Inc. v. Miller, 538 U.S. 329, 341-342 (2003) (saving Kentucky “any willing provider" statute from preemption as a state law regulating insurance because of its application to the insurance industry and its risk spreading effects).

${ }^{51}$ Stone, supra note 25, at 80.

${ }^{52}$ S. Rosenbaum et al., "An Assessment of Legal Issues Raised in High Performing Health Plan Quality and Tiering Arrangements,” (George Washington Univ. Dept. of Health Policy, 2007) available at

O’NEILl INSTITUTE FOR NATIONAL AND GLOBAL HEALTH LAW GEORGETOWN LAW | 600 NEW JERSEY AVENUE NW | WASHINGTON, DC 20001 www.oneillinstitute.org 
http://www.gwumc.edu/sphhs/departments/healthpolicy/chsrp/downloads/Physician_tiering_arrangements_100207. pdf (last visited November 30, 2008).

${ }^{53}$ Crossley, supra note 24, at 86.

${ }^{54} \mathrm{Id}$. at $86-87$.

5542 U.S.C. $\S 2000 \mathrm{e}-2$ (2008).

${ }^{56} \mathrm{Id}$.

${ }^{57}$ Crossley, supra note 24 , at 86-87.

${ }^{58}$ S. Rosenbaum and J. Teitelbaum, “Civil Rights Enforcement in the Modern Healthcare System: Reinvigorating the Role of the Federal Government in the Aftermath of Alexander v. Sandoval," Yale Journal of Health Policy, Law and Ethics, 3 (2003): 215-252, at 217.

59 In Linton v. Carney, 779 F. Supp. 925, 932 (M.D. Tenn. 1990), perhaps the clearest case decided on the issue, Medicaid plan administration payment practices that resulted in racially segregated nursing home facilities were struck down as violating Title VI. For a general discussion of Title VI in a health care context see S. Rosenbaum and J. Teitelbaum, "Civil Rights Enforcement in the Modern Healthcare System: Reinvigorating the Role of the Federal Government in the Aftermath of Alexander v. Sandoval,” Yale Journal of Health Policy, Law and Ethics, 3 (2003): 215-252.

${ }^{60}$ Crossley, supra note 24 , at 87.

${ }^{61}$ Id. See also Stone, supra note 25 , at 81.

${ }^{62}$ Pear, supra note 26.

${ }^{63}$ Id. See also Crossley, supra note 24 at 887-89.

${ }^{64}$ Id. at 90.

${ }^{65} \mathrm{Id}$.

${ }^{66}$ Crossley, supra note 24 , at 88-89.

${ }^{67}$ Id. at 96.

${ }^{68} \mathrm{Id}$. at 95.

${ }^{69} \mathrm{Id}$. at $97-98$.

${ }^{70} 42$ U.S.C. $\S 12112$ (2008).

${ }^{71} 42$ U.S.C. $\S 12132$ (2008).

${ }^{72} 42$ U.S.C. $\S 12182$ (2008).

7329 U.S.C. § 794 (2008).

${ }^{74} 42$ U.S.C. § 12111(8) (2008).

${ }^{75} 29$ U.S.C. § 705(20) (2008).

${ }^{76}$ Bradgon v Abbott, 524 U.S. 624, 630-631 (1998).

${ }^{77}$ See e.g., Gonzales v. Garner Food Services Inc., 89 F. 3d 1523 (11th Cir., 1996); reh. en. banc den. (1996); cert. den. sub. nom. 520 U. S. 1229 (1997).

${ }^{78}$ Olmstead v. L.C., 527 U.S. 581, 589-590 (1999).

${ }^{79}$ K. Pollitz and R. Sorian, “Ensuring Health Security: Is the Individual Market Ready for Prime Time?” Health Affairs Web Exclusive, (October 23, 2002): 372-376, at 372-373, available at http://content.healthaffairs.org/cgi/content/full/hlthaff.w2.372v1/DC1.

${ }^{80}$ See discussion of the ADA insurance safe harbor in Doe v. Mutual of Omaha, 179 F.3d 557 (7th Cir. 1999).

${ }^{81}$ Alexander v Choate, 469 U.S. 287, 302-303 (1985) (upholding Tennessee's 14-day limitation on annual in-patient hospital days covered by Medicaid); Rodriguez v. City of New York, 197 F.3d 611 (2nd Cir.1999) (upholding a distinction between physical and mental disability in the New York Medicaid program's payment for in-home “cueing” services).

${ }^{82}$ Doe, 179 F.3d at 563 (upholding caps in medical insurance policy benefits for AIDS). See also Gonzalez, 89 F.3d 1523 (involving AIDS treatment exclusions in a Title I context).

${ }^{83} \mathrm{Id}$.

${ }^{84}$ G. Cowart, "HIPAA Nondiscrimination and Portability Updated and Expanded,” American Law Institute American Bar Association Continuing Legal Education, 91 (2007): 97.

${ }^{85} \mathrm{Id}$. at 100.

${ }^{86} \mathrm{Id}$.

${ }^{87}$ Id.

${ }^{88} \mathrm{Id}$. at $100-101$.

${ }^{89} \mathrm{Id}$. at $101-102$.

${ }^{90} \mathrm{Id}$.

${ }^{91} \mathrm{Id}$. at 103.

${ }^{92}$ Id. at 99. 
${ }^{93}$ Id.

${ }^{94}$ Rescission of Individual Health Insurance Policies Before the House Committee on Oversight and Government Reform (July 17th, 2008) (statement of A. Block, Director, Center for Drug and Health Plan Choice, Centers for Medicare and Medicaid Services), available at http://oversight.house.gov/documents/20080717111126.pdf (last visited December 11, 2008), 3-4.

${ }^{95}$ See Cowart, supra note 84, at 99-100.

${ }^{96}$ Id.

${ }^{97}$ Id.

${ }^{98}$ An indication of the virtual absence of federal oversight can be found in guidance issued by the Centers for Medicare and Medicaid Services, which is charged with enforcement of the non-discrimination provisions in the state-regulated market. Guidelines at the CMS website provide an extraordinarily abbreviated, incomplete, and cryptic explanation of the non-discrimination provisions, the absence of any detailed information about state obligations, and the absence of any guidance regarding procedures for filing a complaint. In other words, not only is there no regulatory oversight, a clear pathway for individual enforcement (assuming that any consumer ever would recognize a discrimination problem) is completely lacking. Centers for Medicare \& Medicaid Services, Health and Human Services, "Health Insurance Reform for Consumers,” available at http://www.cms.hhs.gov/HealthInsReformforConsume/ (last visited December 11, 2008).

${ }^{99}$ Cowart, supra note 84, at 105.

${ }^{100}$ M. Mulveon, K. Davenport, E.M. Whelan, “High Risk Insurance Pools: A Flawed Model for Reform,” Center for American Progress, available at http://www.americanprogress.org/issues/2008/09/flawed_model.html (last visited December 11, 2008).

${ }^{101}$ Hailey v. California Physicians’ Service, 158 Cal. App. 4th 452 (2007); see also Business Practices in the Individual Health Insurance Market: Termination of Coverage Before the H. Committee on Oversight and Government Reform, $11^{\text {th }}$ Cong. (2008), available at http://oversight.house.gov/story.asp?ID=2089 (last visited December 11, 2008).

${ }^{102}$ Cowart, supra note 84, at 130.

${ }^{103} \mathrm{Id}$. at $126-133$.

${ }^{104} \mathrm{Id}$.

${ }^{105} \mathrm{Id}$. at 126.

${ }^{106} \mathrm{Id}$.

${ }^{107} \mathrm{Id}$. at 115.

${ }^{108} \mathrm{Id}$. at $115-119$.

${ }^{109}$ Id. at 116.

${ }^{110} \mathrm{Id}$. at 121.

11129 C.F.R. § 2590.702(g) (2008).

${ }^{112}$ Id.

${ }^{113}$ For a discussion of HIPAA non-discrimination and wellness programs, see M. Mello, "WWellness Programs and Lifestyle Discrimination - The Legal Limits” N. Engl. J. Med., 359, no. 2 (July 10, 2008): 192-199 (July 10, 2008$).$ 11429 U.S.C. $\S 1182(b)$ (2008).

${ }^{115}$ Id.; 42 U.S.C. § 300gg-1(b) (2008).

11629 U.S.C. § 1182(d) (2008); 42 U.S.C. § 300gg-1(d)(1) (2008).

${ }^{117}$ For a thoughtful review of GINA's limitations see M.A. Rothstein, “Is GINA Worth the Wait?” Journal of Law, Medicine \& Ethics, 36 (2008): 174-177.

${ }^{118}$ Paul Wellstone and Pete Domenici Mental Health Parity and Addiction Equity Act of 2008, Pub. L. 110-343 (2008) (amending 26 U.S.C. § 9812, 29 U.S.C. § 1185a, and 42 U.S.C. § 300gg-5).

11929 U.S.C. § $1185 \mathrm{a}(3)(\mathrm{B})(\mathrm{ii})(2008)$.

12029 U.S.C. $\S 1185 a(3)(B)(i)$ (2008).

12129 U.S.C. $\S 1185 a(3)(B)(i i i)$ (2008).

12229 U.S.C. § 1185a(5) (2008).

12329 U.S.C. § 1185a(4) (2008).

12429 U.S.C. § 1185a(b)(2) (2008).

${ }^{125}$ See, e.g., the expression of coverage of physical therapy in Bedrick v. Travelers Ins. Co., 93 F.3d 149 (4th Cir. 1996), which expressed physical therapy as a broad coverage class and delegated authority to the insurer to make specific medical necessity decisions.

${ }^{126} \mathrm{Id}$.

O’NEILL INSTITUTE FOR NATIONAL AND GLOBAL HEALTH LAW 
${ }^{127}$ See, e.g., McGann v. H. \& H. Music Co., 946 F.2d 401 (5th Cir. 1991), which involved the failed effort to challenge an HIV/AIDS treatment cap. The challenge was rejected as an impermissible claim, since the cap existed as a "macro" limitation on coverage, that is, part of plan benefit design.

${ }^{128}$ Jones v. Kodak Medical Assistance Plan, 169 F.3d 1287, $1292\left(10^{\text {th }}\right.$ Cir. 1999) (upholding ERISA plan administrator's denial of coverage for inpatient alcohol abuse treatment because decision was based on the contractual coverage specifications and an appeal was thus barred).

${ }^{129}$ Cowart, supra note 84 , at 173-175.

${ }^{130} \mathrm{Id}$.

${ }^{131}$ Id.

${ }^{131}$ Cowart, supra note 84 , at $185-186 .$.

${ }^{132}$ Cowart, supra note 84 , at 185-186.

13329 C.F.R. § 2560.503-1(h) (2008).

${ }^{134}$ See Mello, supra note 113.

${ }^{135}$ Doe v. Mutual of Omaha, 179 F.3d 557 (7th Cir. 1999).

${ }^{136}$ America's Health Insurance Plans, supra note 4.

13729 U.S.C. \$1181(c), related to HIPAA portability, offers the basic definition of creditable coverage, which signals a form of health care financing recognized as "coverage" for purposes of federal health benefit laws.

${ }^{138}$ See American Medical Sec., Inc. v. Bartlett, 111 F.3d 358 (4th Cir., 1997) for a discussion of federal preemption under ERISA of state efforts to regulate self insured plans by regulating the reinsurance market.

13942 U.S.C. $\$ 1397 \mathrm{cc}(\mathrm{a})$

14042 U.S.C. §423.578. For a discussion of the Part D exceptions process see V. Gottlich, “The Exceptions and Appeals Process: Issues and Concerns In Obtaining Coverage Under the Medicare Part D Prescription Drug Benefit,” Kaiser Family Foundation, available at http://www.kff.org/medicare/upload/The-Exceptions-and-AppealsProcess-Issues-and-Concerns-in-Obtaining-Coverage-under-the-Medicare-Part-D-Prescription-Drug-Benefit-IssueBrief.pdf (last visited January 25, 2009): 4-6. In 2007, reversal rates for exceptions requests for non-formulary drugs ran at $48 \%$ according to the Centers for Medicare and Medicaid Services, which administers the part D program. Fact Sheet, Part D Reconsideration Appeals Data 2007, available at http://www.cms.hhs.gov/MedPrescriptDrugApplGriev/Downloads/DReconAppealsData2007.pdf (last visited December 14, 2008).

${ }^{141}$ Metropolitan Life Insurance Co. v Glenn, 128 S. Ct. 2343 (2008).

${ }^{142}$ See e.g., Bipartisan Patient Protection Act, S. 872, 107th Cong. §1(a)103-104.

${ }^{143}$ See P. Cunningham, "Mounting Pressures: Physicians Serving Medicaid Patients and the Uninsured, 1997-2001,” Center for Studying Health System Change, available at http://www.hschange.com/CONTENT/505/?words=medicaid+provider+participation (last visited December 14, 2008). A docket of Medicaid cases to improve provider participation underscores the urgency of the problem. National Health Law Program, "Docket of Medicaid Cases to Improve Provider Participation" (2003), available at http://www.nls.org/conf2003/provider-docket.htm (last visited December 14, 2008).

14442 U.S.C. $\$ 1396 a(a)(30)$. For a review of the Medicaid "equal access” provision as it is known, see S. Rosenbaum, "Understanding Medicaid's “Equal Access” Law in the Context of Private Enforcement Actions” California Health Care Foundation, 2008.

${ }^{145}$ S. Rosenbaum, A. Markus, J. Scheer, M. E. Harty, "Negotiating the New Health System at Ten: Medicaid Managed Care and the Use of Disease Management Purchasing" Center for Health Care Strategies, 2007, available at http://www.chcs.org/publications3960/publications_show.htm?doc_id=684299 (last visited December 14, 2008). ${ }^{146}$ Rosenbaum, supra note 9, at 635.

${ }^{147}$ See e.g., 42 U.S.C. \$1396n, authorizing the provision of home and community based waiver services for certain individuals whose health conditions require an institutional level of care.

${ }^{148}$ See e.g., Medicaid's optional coverage of individuals with disabilities who have excess earnings and are ineligible for Supplemental Security Income. 42 U.S.C. §1396a(a)(10)(A)(ii)(XV) (2008).

O’NEILl INSTITUTE FOR NATIONAL AND GLOBAL HEALTH LAW 